\title{
A buckling behavior of elliptic perforated steel CHS columns exposed to axial compression load
}

\author{
Tuğrul BÖLÜKBAŞ ${ }^{a^{*}}$ (D), Osman Hamdi METEa \\ aDepartment of Mechanical Engineering, Sakarya University, Sakarya, Turkey. E-mail: tugrul.bolukbas@ogr.sakarya.edu.tr, \\ ohmete@sakarya.edu.tr
}

* Corresponding author

http://dx.doi.org/10.1590/1679-78255908

\begin{abstract}
Maintenance work is very important for the continuation of the long service periods planned in engineering structures. Some damage to the steel elements, such as the growth of the holes in the structure, leads to reduced buckling strength and shortened service life. Moreover, the criterion of the hole is uncertain for steel structures. For this reason, it is very important to predict and evaluate the buckling strength of a damaged structure and to take necessary measures. Therefore, in this article, a series of systematic experimental studies are carried out to calculate the buckling strength of elliptical perforated steel columns. Deformation shapes and load-displacement graphs of the test columns are plotted. In addition, the behavior of the column under axial load is analyzed by constructing a finite element model. Numerical simulations are performed with Dynaform finite element package. The effect of the elliptical hole on the column buckling strength by changing the width, height and center is investigated numerically and experimentally. Prepared samples are subjected to axial loading test and compared with numerical results. In light of the data obtained from the numerical results, the effect of the width, height and center of a single elliptical hole on the buckling strength of the column is clearly demonstrated.
\end{abstract}

Keywords

Axial compression, Circular hollow section (CHS), Elliptic hole, Finite element program (Dynaform), Experimental study, Taguchi methods

\section{Graphical Abstract}
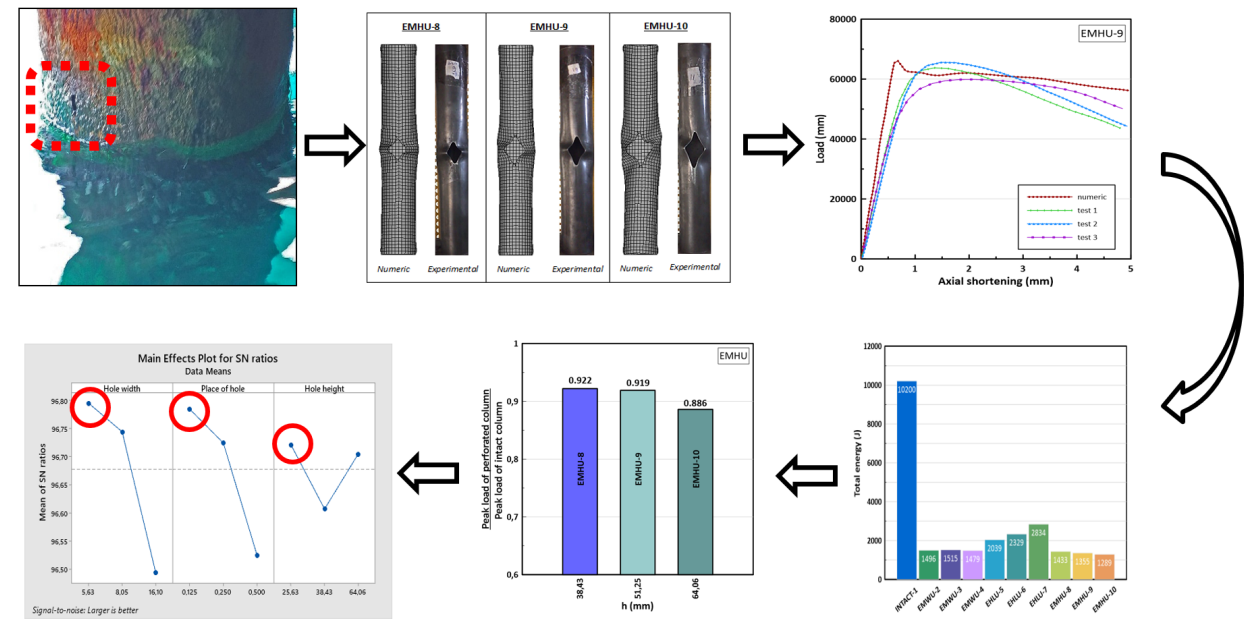

Received: December 19, 2019. In Revised Form: April 29, 2020. Accepted: May 10, 2020. Available online: May 13, 2020 https://doi.org/10.1590/1679-78255908 


\section{INTRODUCTION}

Circular cylindrical elements are frequently used in some engineering structures such as the automobile industry, shipbuilding, natural gas main lines, fixed offshore platforms and bridges. These elements operate under axial compression loads. The effect of the holes on the buckling load and deformation shapes of the steel elements is an important criterion in the design of the structures. It depends on revealing all uncertainties on the structure in order to provide the desired structural performance during the planned service.

Due to the geometric holes that can be drilled for connection or the influence of environmental factors (corrosion, any external impact), they can form holes in the steel structures. The growth of these holes can have negative effects on the load carrying capacity and stability of the systems.

Many researchers have conducted studies on the determination of the cylindrical shell buckling load. At first, the classical theory equation was first determined by Timoshenko and Gere (1961). According to the classical theory, the buckling load of thin cylindrical shells subject to uniform axial compression can be calculated using the equation (1).

$N_{c r}=\frac{E}{\sqrt{3\left(1-\vartheta^{2}\right)}}\left(\frac{t^{2}}{R}\right)$

where $\mathrm{N}_{\mathrm{cr}}$ is the cylinder classical elastic buckling load, $\mathrm{E}$ is the Young modulus, $\vartheta$ is the Poisson's ratio, $\mathrm{t}$ is wall thickness and $\mathrm{R}$ is shell radius.

Then, Toda (1983) conducted experimental studies to clarify the effects of size of circular holes on the buckling of circular cylinders under axial compression. Jullien and Limam (1998) examined the stability problem of perforated cylindrical shells. In the study, the dimensions and shape of the hole were investigated parametrically. Beside proved that the buckling capacity of thin cylindrical shells was often much lower than that predicted in the classical theory. Ifayefunmi (2016) investigated the buckling behavior of short mild steels with length (L:118.8 mm), diameter (D:100 mm) and three different thickness ( $\mathrm{t}: 0.5,1.0,2.0 \mathrm{~mm})$ using experimental and FE methods.

Umbarkar et al. (2013); Feng et al. (2016); Rouzegar and Elahi (2016); Lee et al. (2017); Rouzegar et al. (2018) focused on the effect of size, number of hole and location in their research. Shariati and Rokhi (2008) investigated the effect of elliptic holes on thin-walled cylindrical steels using numerical and experimental methods. In this study, thinwalled cylindrical shells with three different lengths (L: $120,273,420 \mathrm{~mm}$ ) and two different diameters (D:42, $48.1 \mathrm{~mm})$ were analyzed. They demonstrated the effect of length-diameter $(L / D)$, cutout position and diameter-thickness $(D / t)$ ratios on the buckling and post-buckling behavior of cylindrical shells.

Shariati et al. (2010) in order to determine the buckling load of cylindrical panels and to investigate the behavior of the panels post buckling, they performed numerical and experimental studies under axial compression load.

Effect of corrosion damage on buckling strength of structures were performed by Oszvald (2014); Nazari et al. (2014); Karagah et al. (2015).

Some researchers applied different imaging techniques to determine the buckling load. Vaz et al. (2018) used three-dimensional laser scanning and ultrasonic thickness measurements and Zhao et al. (2018) used the three-dimensional digital image correlation method.
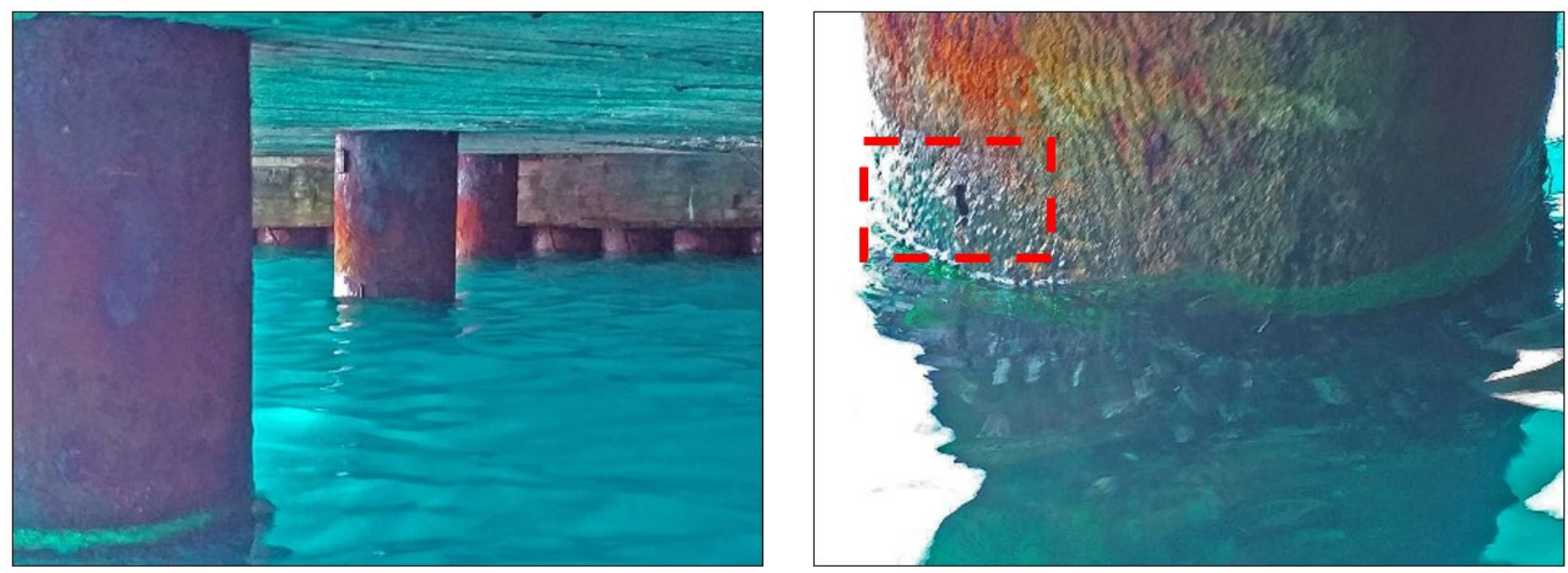

Figure 1 Elliptic shaped hole formation in columns 
In recent years, some researchers have applied various strengthening methods. Ghazijahani et al. (2015) used a reinforcement method by welding plates around the holes to reduce the structural effect of the differently shaped openings on the tubes. Hou et al. (2019) used filament winding technique in their studies. They found axial compression performance and fracture modes of hybrid tubes. Nabati and Ghazijahani (2020) investigated the effects of Carbon Fibre Reinforced Polymer strengthening of circular steel tubes with cutouts on the axial load bearing capacity.

The main purpose of this study is to reveal the effects of the geometric characteristics of the holes in the elliptical perforated steel columns operating under axial loading on deformation shape and load-displacement diagram.

Elliptical perforated damages detected under corrosive conditions of the steel supporting legs of a pier of an active port in territorial waters (Figure 1).

\section{EXPERIMENTAL RESEARCH}

In this section, experimental studies were carried out under the titles of the test equipment, test sample, tensile test and compression test. The terminology was formed by classifying the prepared samples.

\subsection{Test Equipment}

In order to investigate the effect of the geometric properties of the hole on the buckling strength of the column, a series of tests were performed under axial loading by drilling holes of desired dimensions. In the experimental research, Hursan brand DCP 77/640 model hydraulic press with a capacity of $250 \mathrm{kN}$ and a delivery speed range of 1-8 mm/s was used (Figure 2). Calibration of the test device was performed by Turkish Standards Institution (TSE).

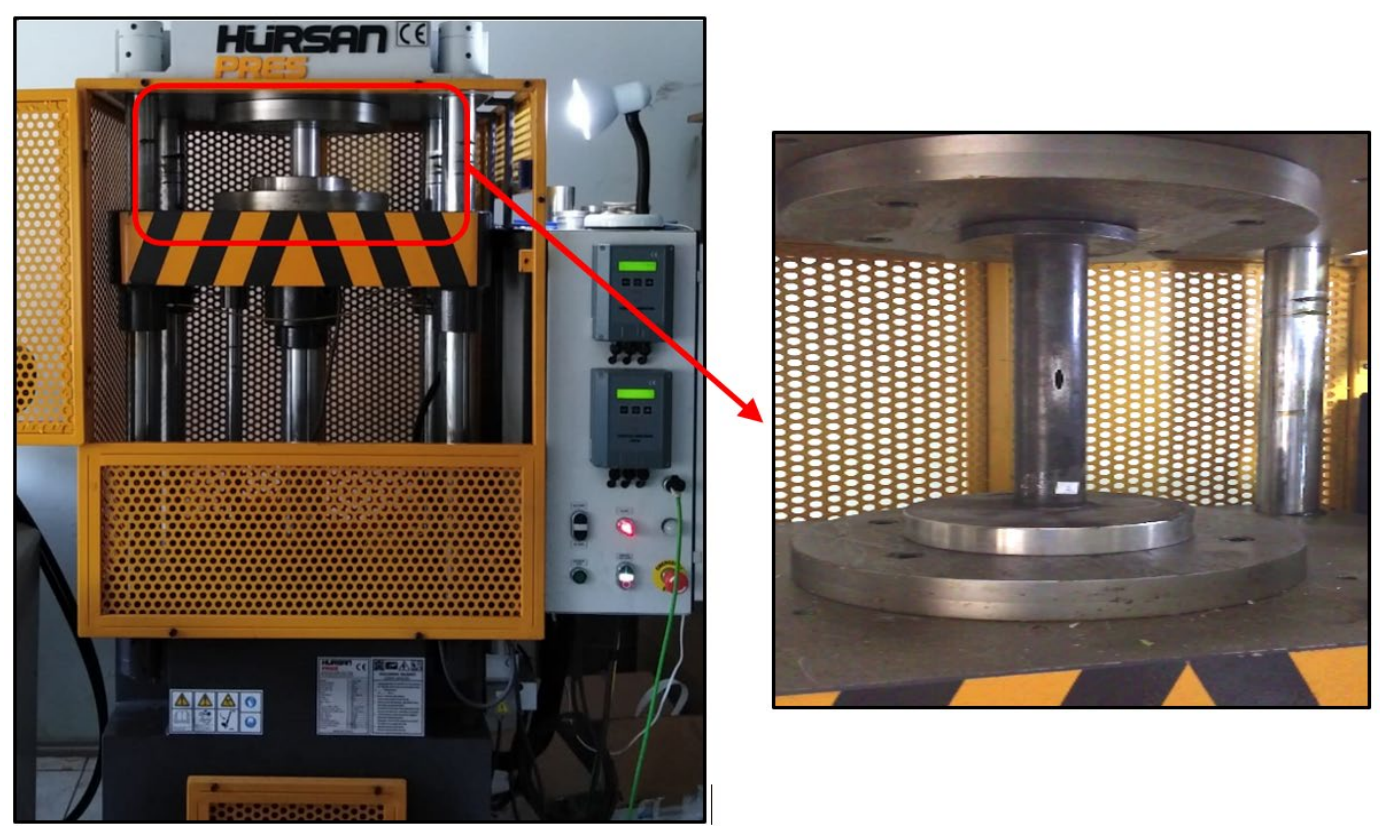

(a)

(b)

Figure 2 Uniaxial compression test equipment (a) initial set up of specimen between hursan platens; (b) final set up with the hursan platen clamping the specimen to provide required edge support

In the four-column hydraulic press, force values were measured with $250 \mathrm{kN}$ load-cell and displacement values with magnetic extensometer. As a result of the experiments, instantaneous force-displacement $(\mathrm{N}-\mathrm{mm}) \mathrm{data}$ pair was obtained.

\subsection{Test Sample}

The test specimens were chosen geometric size such as D: $51.25 \mathrm{~mm}, \mathrm{~L}: 327.93 \mathrm{~mm}, \mathrm{t}: 1.36 \mathrm{~mm}$. Hole width (w), hole height $(\mathrm{h})$, center of the hole $(\mathrm{e})$ and place of the hole $(\mathrm{e} / \mathrm{L})$ parameters were used to express the elliptic size. Test samples with mild steel properties were used. The appearance of the cylindrical column with elliptical hole schematic technical drawing and figure are as in Figure 3. Both ends of the samples were processed to be smooth in order to make 
proper contact with the rigid plate. Okuwa Seiki CNC vertical machining center was used to make elliptical shaped holes on the samples. The test samples are labeled to avoid any confusion.

As mentioned, the aim of this study is to determine the effect of the elliptical hole's geometric properties and its location on the column on the buckling behavior. Samples were formed in three different groups except the intact column. The first group was named Elliptical Measure Width Unstable (EMWU), the second group was named Elliptical
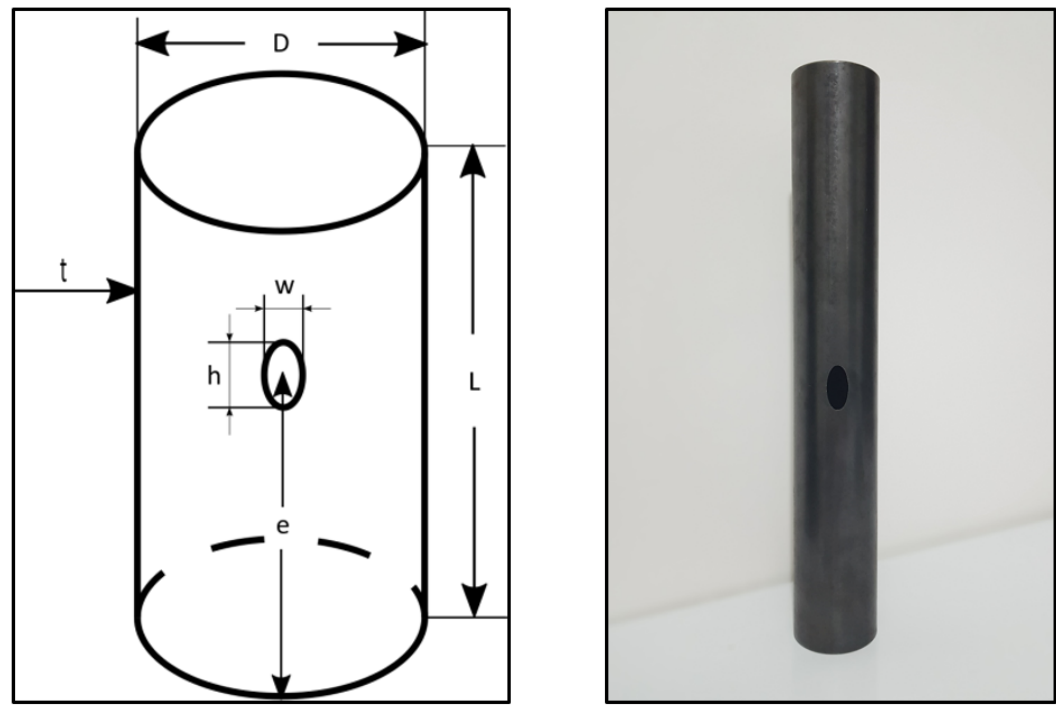

Figure 3 Schematic technical drawing and elliptical perforated column photo

Hole Location Unstable (EHLU) and the third group was Elliptical Measure Height Unstable (EMHU). In the first group, the height of the elliptical hole was kept constant while the width was changed to be $5.63 \mathrm{~mm}, 8.05 \mathrm{~mm}$ and $16.10 \mathrm{~mm}$. In the second group, the width and height of the elliptical hole were fixed, while the position on the column was changed to $0.375 \mathrm{~L}, 0.25 \mathrm{~L}$ and $0.125 \mathrm{~L}$ instead of $0.5 \mathrm{~L}$ in contrast to the holes in the other group. In the last group, the width of the elliptical hole was kept constant while the height was changed to $38.43 \mathrm{~mm}, 51.25 \mathrm{~mm}$ and $64.06 \mathrm{~mm}$. The intact sample was used as a comparison in the experimental study (Table 1).

Table 1 Geometrical characteristics of perforated samples

\begin{tabular}{ccc}
\hline Sample & Size of elliptic hole $[\mathbf{w x h}](\mathrm{mm})$ & Place of hole (e/L) \\
\hline INTACT-1 & $\ldots . . .$. & 0.5 \\
EMWU-2 & $5.63 \times 25.625$ & 0.5 \\
EMWU-3 & $8.05 \times 25.625$ & 0.5 \\
EMWU-4 & $16.10 \times 25.625$ & 0.375 \\
EHLU-5 & $12.07 \times 25.625$ & 0.25 \\
EHLU-6 & $12.07 \times 25.625$ & 0.125 \\
EHLU-7 & $12.07 \times 25.625$ & 0.5 \\
EMHU-8 & $12.07 \times 38.430$ & 0.5 \\
EMHU-9 & $12.07 \times 51.250$ & 0.5 \\
EMHU-10 & $12.07 \times 64.060$ & \\
\hline
\end{tabular}

In order to demonstrate the repeatability of the experiments, 30 test samples were prepared for each case and tested. The position of the drilled holes is directly opposite the welding seam and uncertainties due to residual stresses are avoided.

\subsection{Tensile Test}

The mechanical properties of the sample were required to be used in the finite element analysis. In order to determine the mechanical properties of the column, tensile test specimen in accordance with EN ASTM-E8 standard was prepared and tensile test was performed at $1.5 \mathrm{~mm} / \mathrm{min}$ jaw speed (Figure 4). 
For ductile materials, real diagrams in compression and tensile tests have been determined to compatibility with each other Cottrel (1964). Some empirical equations have been developed, similar to the experimentally obtained true stress-true strain curves. One of them is given below by the equation (2) in constant temperature and constant strain rate put forward by Ludwing.

$\sigma=\sigma_{0}+K \varepsilon^{n}$

Where; $\sigma_{0}$ is the yield stress, $\mathrm{K}$ is the strength coefficient, $\varepsilon$ is the strain, $\mathrm{n}$ is the hardening exponent.

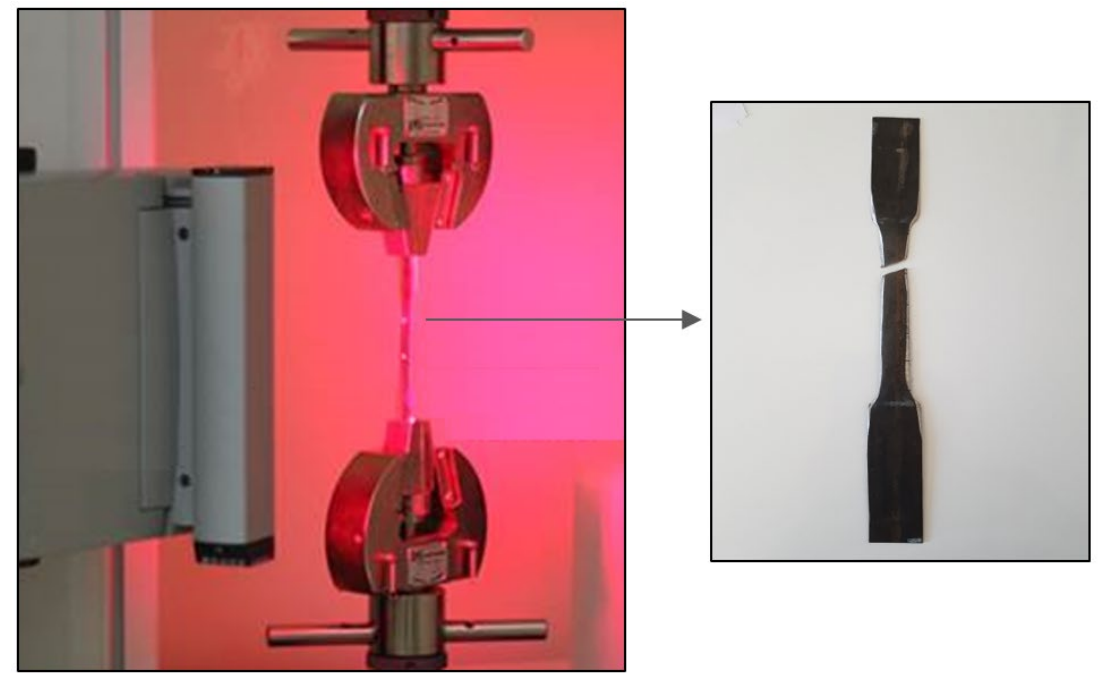

Figure 4 Tensile test equipments (Instron) and after tensile test view of the specimen

The results obtained from the tensile test are given in the table below (Table 2). Stress-strain relationship was ob-tained by the same test (Figure 5). By using the experimental data, the strength coefficient (K) and hardening exponent $(n)$ of the material were calculated.

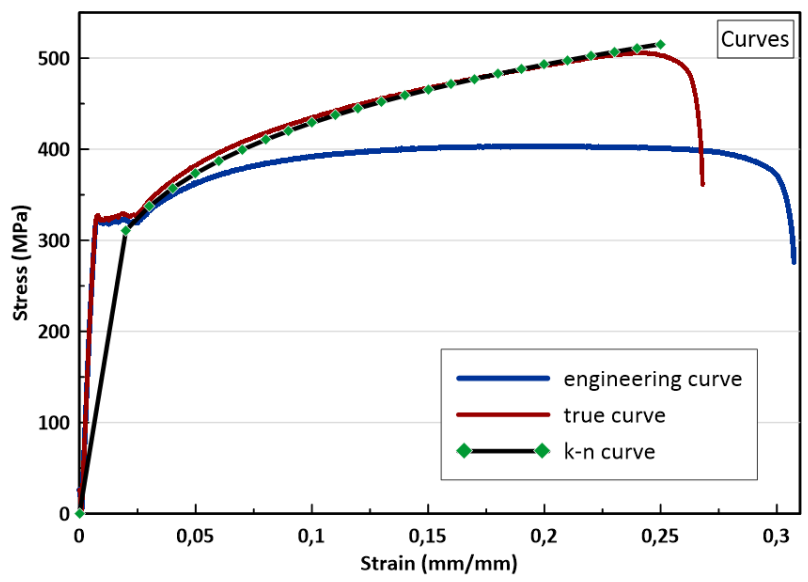

Figure 5 Stress-strain curves

Table 2 Mechanical properties of the sample

\begin{tabular}{cccccccc}
\hline$\sigma_{0,2}(\mathrm{M})$ & $\mathrm{E}(\mathrm{MPa})$ & $\mathbf{v}$ & $\boldsymbol{\sigma}_{\mathrm{u}}(\mathrm{MPa})$ & $\boldsymbol{\varepsilon}_{\mathrm{f}}(\%)$ & $\mathrm{K}$ & $\mathbf{n}$ \\
\hline 320 & 257620 & 0.28 & 422 & 27.4 & 680 & 0.2 \\
\hline
\end{tabular}

\subsection{Compression Test}

Sample was placed between the platens of hursan machine without any clamping plates, as shown in Figure 2a for EMWU-2 specimen. Then, the movable crosshead is gently adjusted until a contact is established between the specimen and the hursan platen, as showed in Figure $2 \mathrm{~b}$. It is assumed that the platen of the hursan machine will helps to provide 
the desirable boundary condition. Though it is practically impossible to achieve fully clamped condition without rotation, but the effect of rotation on the magnitude of buckling load of cylindrical shell has been proven to be marginal Ifayefunmi and Blachut (2011).

The same experimental set up was repeated for other samples. The behavior of the column under load was recorded by video recording. Load-displacement diagram was drawn by applying the axial load. The deformation shapes of the intact-perforated columns subjected to axial loading were also showed (Figures 6a, 6b). Peak load values obtained from experimental studies are given in Table 3.

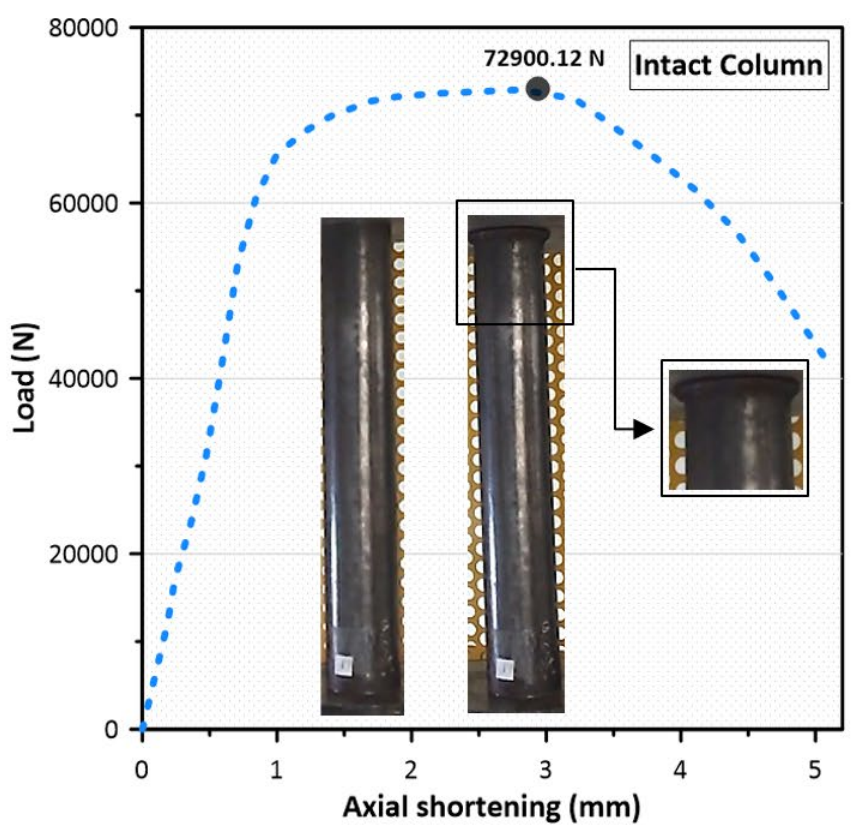

(a)

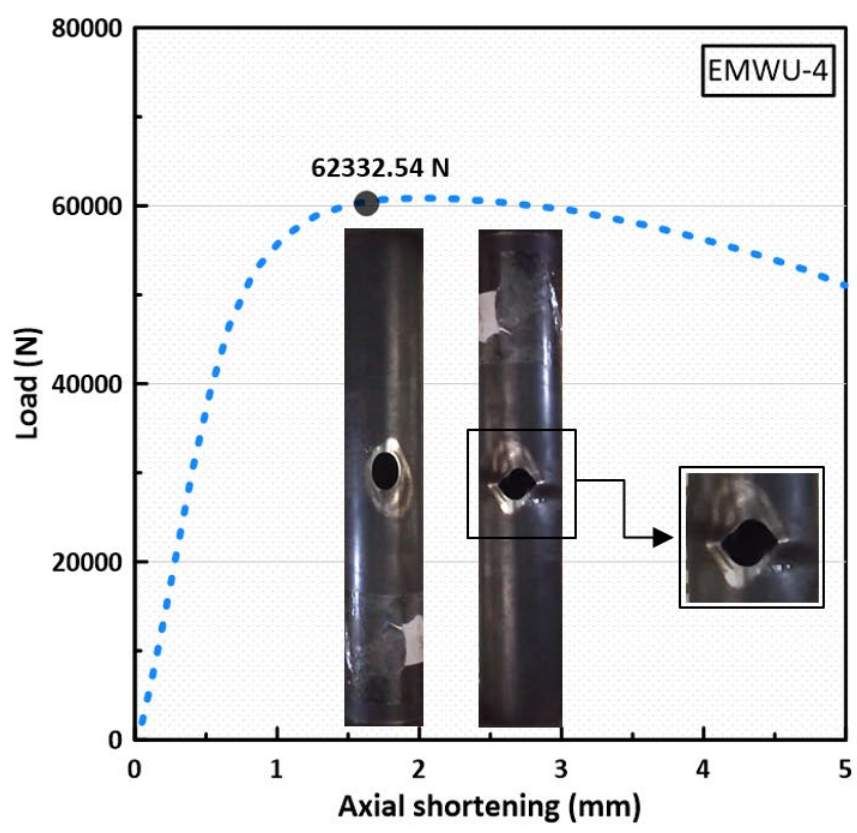

(b)

Figure 6 Load-displacement curves and deformation shapes (a) INTACT-1 column; (b) EMWU-4

Table 3 Peak load $(\mathrm{N})$ values obtained by experimental studies

\begin{tabular}{ccccccccccc}
\hline Sample & Intact-1 & EMWU-2 & EMWU-3 & EMWU-4 & EHLU-5 & EHLU-6 & EHLU-7 & EMHU-8 & EMHU-9 & EMHU- \\
& & & & & & & 10 \\
\hline Test 1 & 75099.34 & 65162.55 & 63976.14 & 60879.25 & 58827.42 & 53458.84 & 59376.05 & 49652.60 & 63752.54 & 59046.23 \\
Test 2 & 74112.66 & 68409.76 & 64408.34 & 58301.79 & 61939.94 & 64447.44 & 66903.84 & 58186.38 & 65586.26 & 57543.97 \\
Test 3 & 72900.12 & 58150.83 & 63313.65 & 62332.54 & 64791.04 & 64174.96 & 67628.82 & 62278.67 & 59884.62 & 58971.48 \\
\hline
\end{tabular}

\section{FINITE ELEMENT MODELLING}

In this section, after obtaining the geometry of the sample in CAD environment, finite element model was created in Dynaform FE program. After assigning element properties, material type and boundary conditions were selected. The last stage was loading.

\subsection{General}

In this study, nonlinear finite element analysis was performed by means of Dynaform 5.7 .3 finite element package program.

There are three basic components in the system. The first one is stationary table (die), the second is moving table (punch) and the third; there is a workpiece exposed to the compressive load between the two tables. Compression modelling used for the analysis is shown in Figure 7a.

\subsection{Separation of elements and material type mesh convergence}

At this stage, firstly the data obtained from tensile tests were loaded into the program. The FEM mesh of the column is shown in Figure $7 \mathrm{~b}$. 
A mesh convergence study was conducted with five different element sizes. As seen in Figure 8, different mesh sizes had negligible effects on the peak load of the perforated column. The CPU time was dramatically increased at element sizes smaller than $5 \mathrm{~mm}$. Mesh size $(5 \mathrm{~mm})$ were adopted for the analyses.

For finite element analysis, Dynaform 5.7.3 package program was used. The material type called “*MAT_018” was selected in analysis. This is an isotropic plasticity model with rate effects which uses a power law hardening rule (Ls-Dyna, 2007). Fully integrated shell element (ELFORM=16) was used in the analysis, which provides four integration points on the element surface Bari (2015), in Figure 9a. Shell elements are two-dimensional elements based on a combination of plane stress assumptions and plate theory.

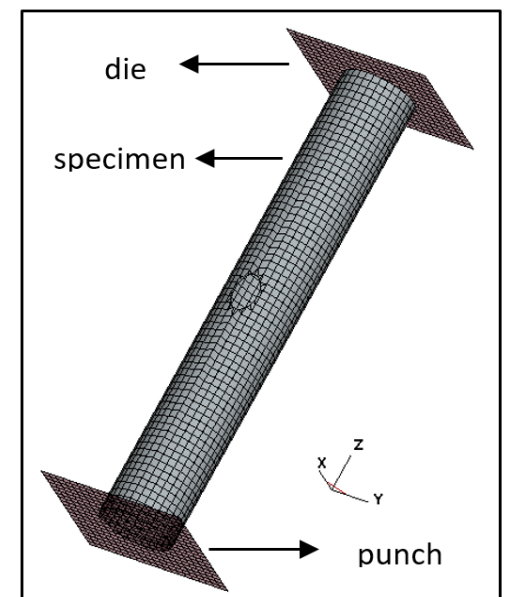

(a)

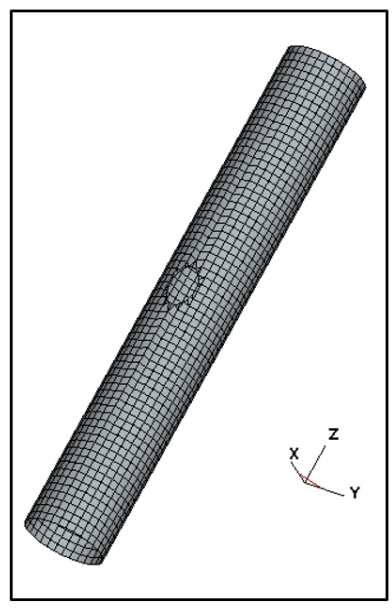

(b)

Figure 7 (a) Compression modeling rigid plates; (b) finite element division of the sample

This is considered reasonable for thin-walled elements. According to Stelzmann (2010), 3-5 points of integration (or more) per element is recommended for a nonlinear material model. The nonlinear dynamic analysis is used in FE method.

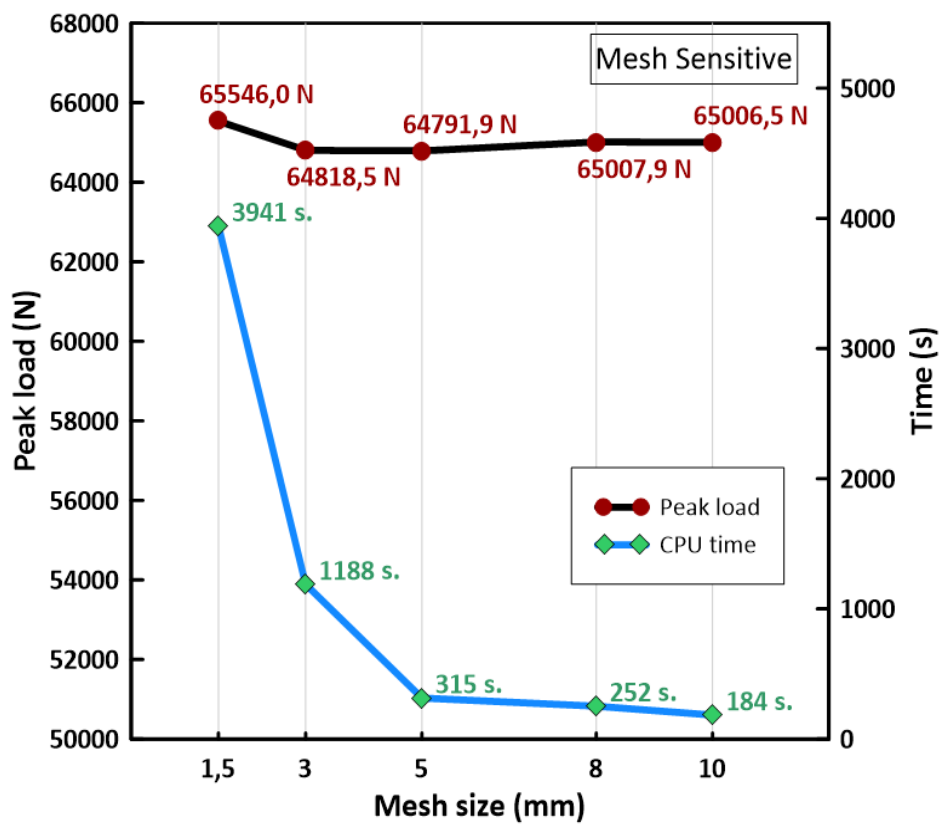

Figure 8 Graph of mesh sensitivity and CPU time for perforated column (EMWU-4) 


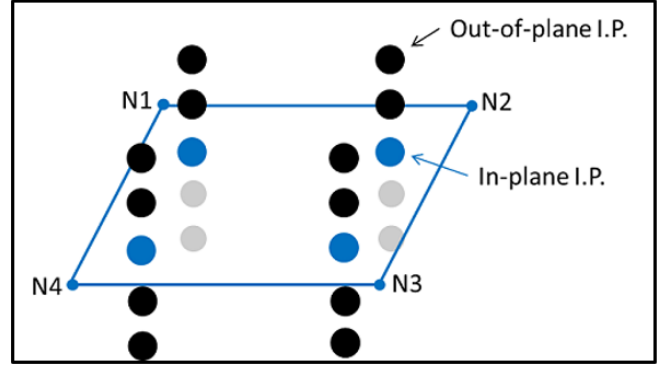

(a)

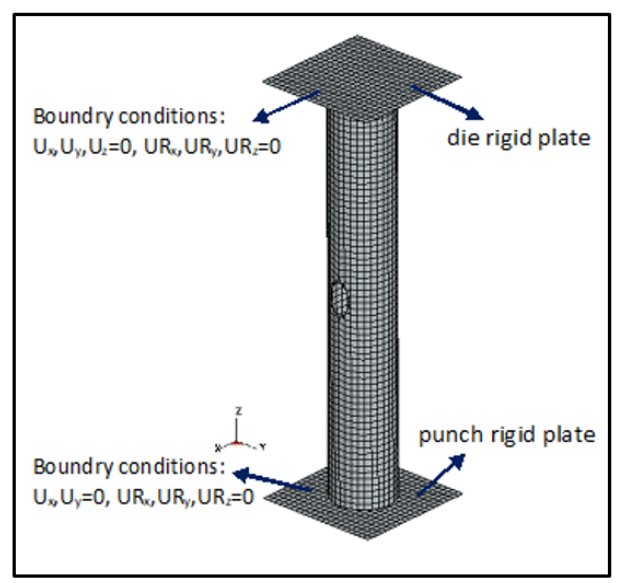

(b)

Figure 9 (a) Element formulation for rectangular shell element; (b) boundary conditions

Boundary conditions were fixed in all directions at the top and bottom ends (Ux,Ux,Uz,URx,URy,URz=0) except for Z-axis (Uz), which was free to displacement at the bottom end (Figure $8 \mathrm{~b}$ ). Rigid plates were used at the top and the bottom of the models to simulate the real loading conditions compared to the experiments. Nabati and Ghazijahani (2020).

\subsection{Reference buckling load}

The reference buckling load, $F_{\text {ref, }}$ is taken as the load required to cause the cylinder to yield and it is designed according to Shariati and Rokhi (2008) as formula (3):

$\mathrm{F}_{\mathrm{ref}}=\pi \mathrm{D} \mathrm{t} \sigma_{\mathrm{y}}$

Where; $F_{\text {ref }}$ is the reference load, $D$ is the diameter, $t$ is the Wall thickness and $\sigma_{y}$ is the yield stress. $F_{\text {ref }}$ is calculated;

$F_{\text {ref }}=\pi \times 51.25 \mathrm{~mm} \times 1.36 \mathrm{~mm} \times 320 \mathrm{~N} / \mathrm{mm} 2=70070.1 \mathrm{~N}$

\subsection{Numerical Simulations}

After the preliminary preparations were completed and finite element analysis was performed. Load-displacement diagram was drawn by applying the axial load. The deformation shapes of the intact-perforated columns subjected to axial loading were also showed.

Peak load values obtained by FE method are given in Table 4.

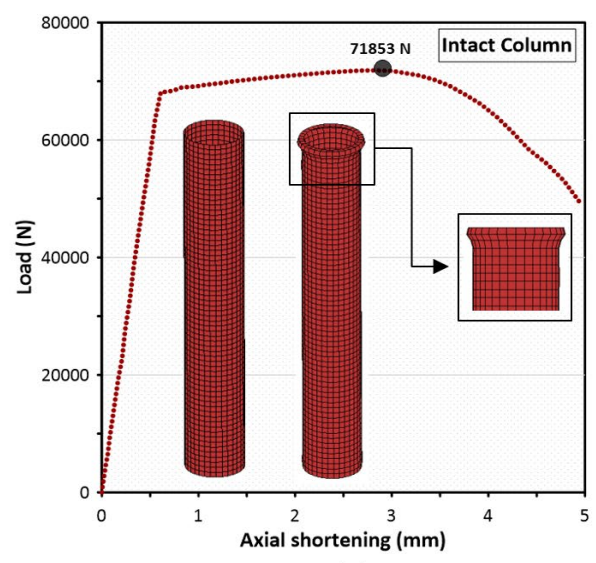

(a)

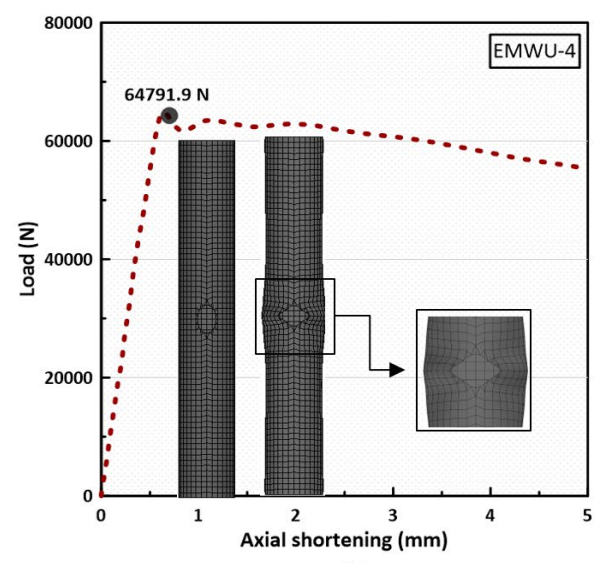

(b)

Figure 10 Numerical simulations graph and details (a) INTACT-1 column; (b) EMWU-4 
Table 4 Peak load $(\mathrm{N})$ values obtained by FE analysis

\begin{tabular}{ccccccccccc}
\hline Sample & INTACT-1 & EMWU-2 & EMWU-3 & EMWU-4 & EHLU-5 & EHLU-6 & EHLU-7 & EMHU-8 & EMHU-9 & EMHU-10 \\
\hline Numeric & 71853 & 68065.6 & 67700.8 & 64791.9 & 67363.7 & 68107.3 & 68426.2 & 66312.7 & 66071.7 & 63706.5 \\
\hline
\end{tabular}

The results of numerical analysis peak load and theoretical prediction based on material data are shown in Table 5 . The results seem to combine well with each other.

Table 5 Comparison of numerical peak load with theoretical prediction

\begin{tabular}{cccc}
\hline Sample & Analysis method & Peak load (N) & Error \\
\hline INTACT-1 & FE Analysis & 71853 & $2.54 \%$ \\
& Theoretical prediction & 70070.1 & \\
\hline
\end{tabular}

\subsection{Energy Absorption}

The total energy absorbed by a column can be defined experimentally as the work of the crushing load. The total energy absorption ( $\mathrm{J}$ ) can be calculated by Equation (4).

$E_{\text {absorbed }}=\int P . d \delta$

Here, $P(N)$ is the crushing load in the axial direction and $\delta(m)$ is the amount of crushing in the axial direction. This

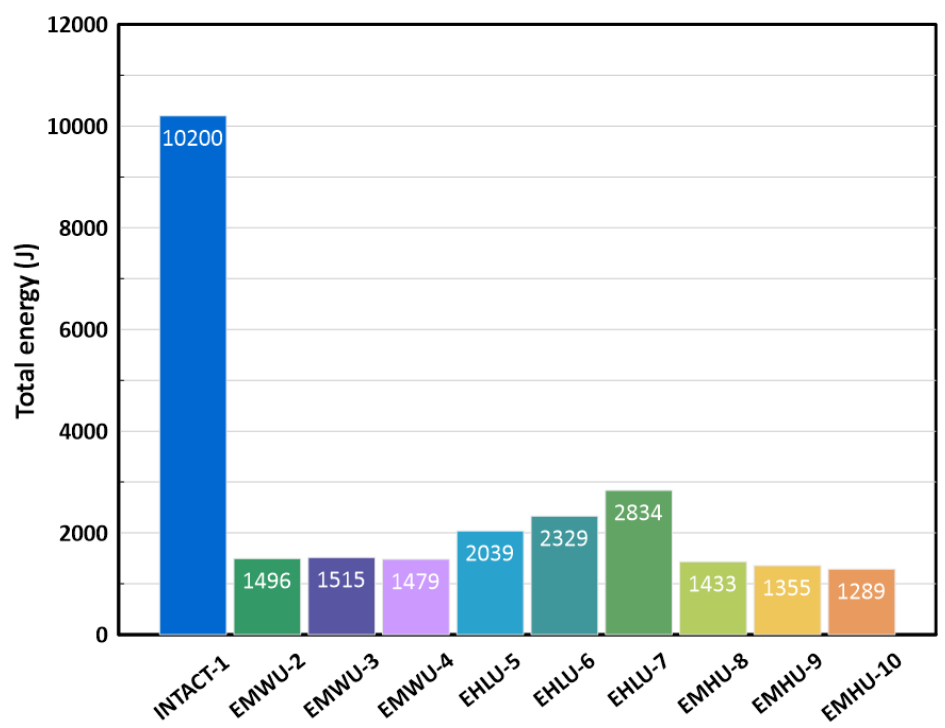

Figure 11 Total energy absorption values obtained by FE analysis

expression is represented by the area under the load-displacement graph obtained for the energy absorber.

As a result of numerical analysis, total energy absorption values of intact-perforated columns were found (Figure 11). The average total energy absorption value of the perforated columns was calculated to be $1752.1 \mathrm{~J}$. When this average value is compared with the intact sample, the total energy absorption value of the perforated columns decreases by $82.82 \%$. This indicates that the hole in the column significantly reduces the energy absorption capability.

\section{TEST AND NUMERIC RESULTS}

Four sets of tests were prepared and tested to investigate the behavior of intact and elliptic perforated samples under axial loading. The deformation shapes and load-displacement diagrams of the tested intact and elliptical perforated samples were compared with the finite element simulations obtained using the Dynaform 5.7.3 package (Figure 12). 
When the axial load was applied to the intact sample, a collar-shaped (elephant foot) collapse began at the top of the column. This deformation shape was found to be the same in both methods (Figures 6a, 10b).

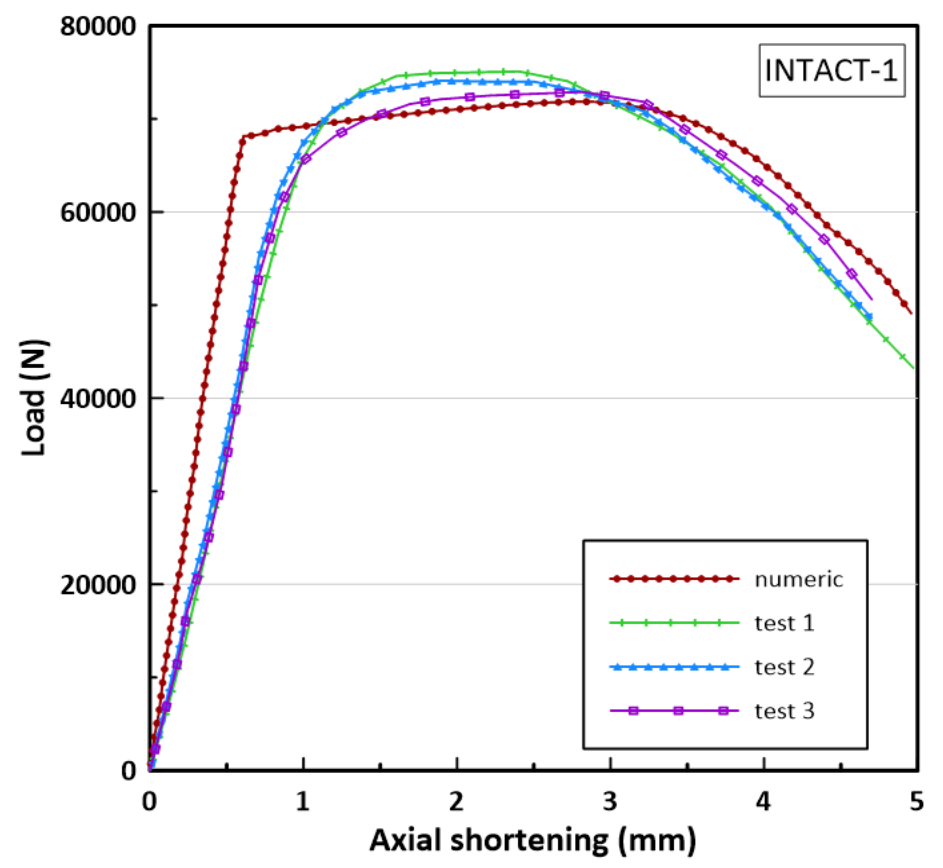

Figure 12 Load-axial shortening behavior and comparison for INTACT-1

Lots of coherent deformation shapes between the two methods were obtained indicating the validity of finite element modeling. For the perforated columns, outward folding mechanisms were formed in the hole region (Figure 13).
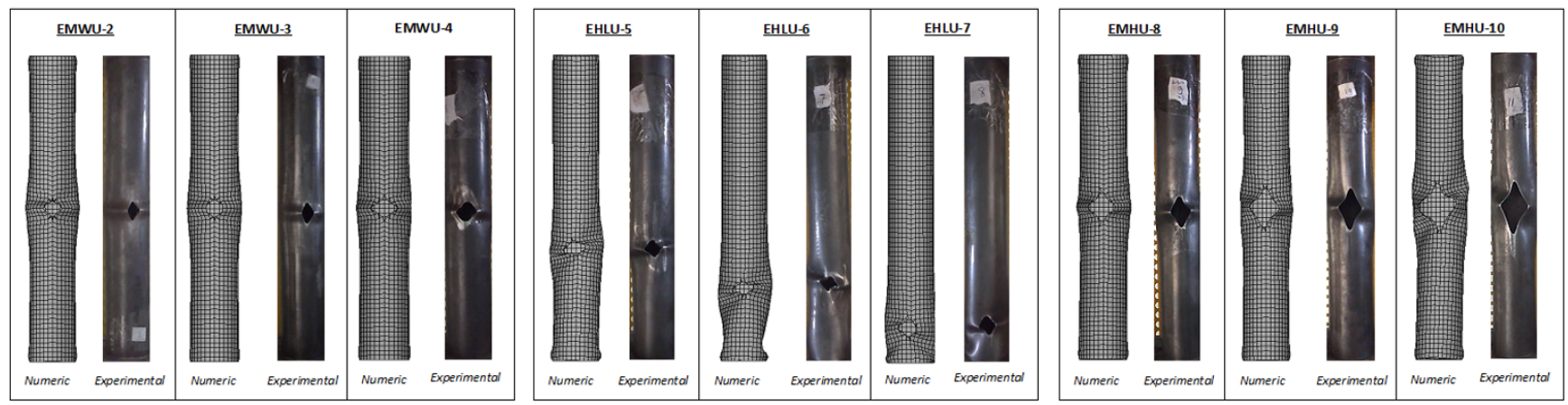

Figure 13 Deformation shapes obtained from experimental and FE analysis

The load-axial shortening diagrams of perforated columns obtained by FE simulations are compared with experimental results (Figures 14, 15 and 16). The difference between the stiffness of the experimental and numerical models can be attributed to material and geometric imperfections, loading imperfections and the presence of longitudinal seam welding. Despite these points, the discrepancies were found to be in an acceptable range.

The load-axial shortening curves obtained from numerical results were carefully examined. After the curve reached the peak point, a sudden decrease in load was observed. The curve continued downwards after drawing the curve deformation plateau. The reason why this phenomenon cannot be obtained clearly in experimental studies is; it relates to the accuracy of the data reading of the test device. This is illustrated in the load-displacement diagram of EMWU-4 in Figure 14. 

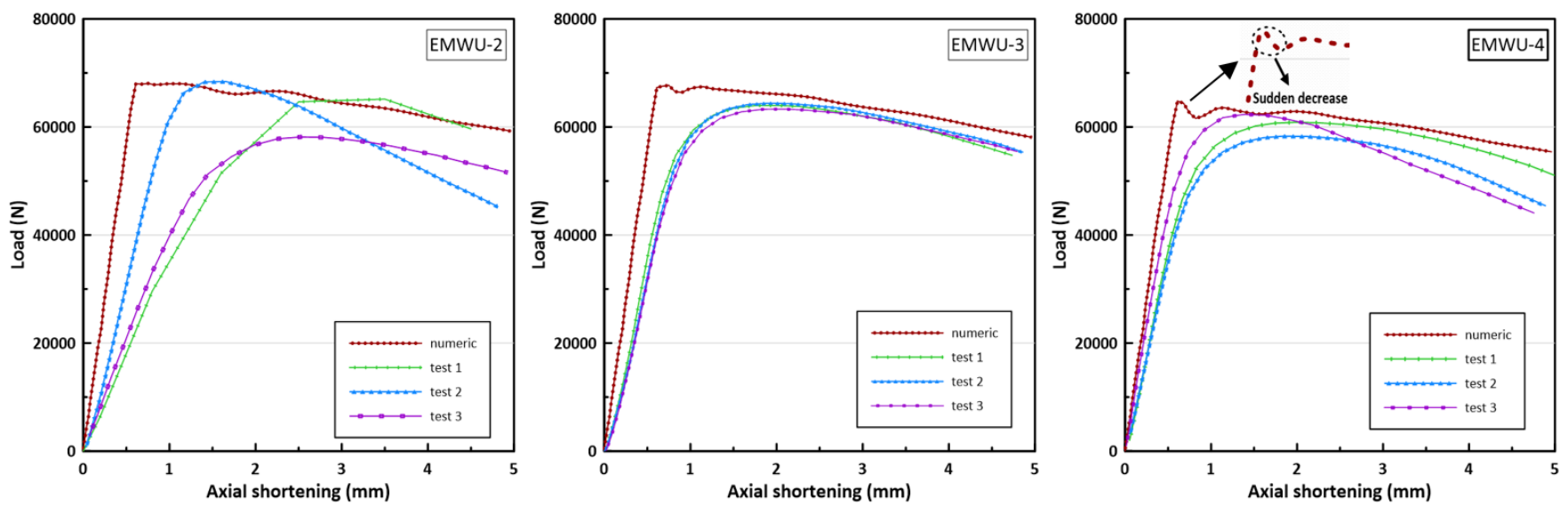

Figure 14 Load-axial shortening behavior and comparison for EMWU-2-3-4
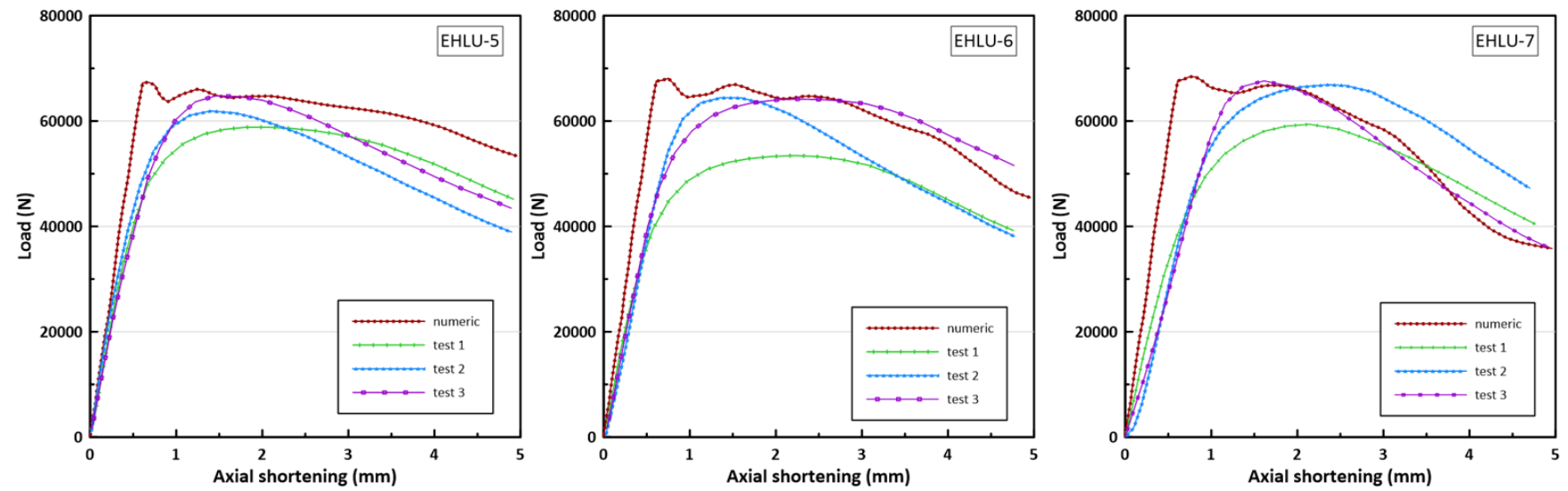

Figure 15 Load-axial shortening behavior and comparison for EHLU-5-6-7
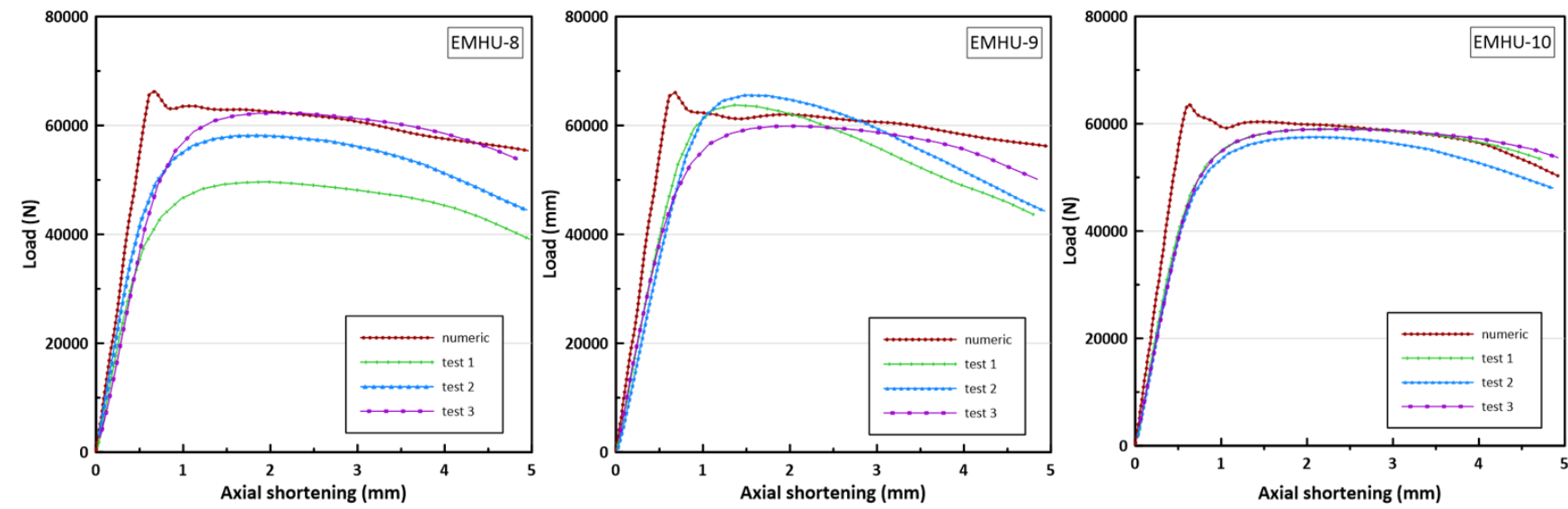

Figure 16 Load-axial shortening behavior and comparison for EMHU-8-9-10

The bar charts below show the peak load variations of the elliptical perforated samples depending on the parameters $\mathrm{w}$, L/e and $\mathrm{h}$ (Figure 17). When the values are evaluated in general terms, the geometric growth of the elliptical hole decreased as the buckling strength. Peak load value decreased by $5.27 \%, 5.78 \%$ and $9.83 \%$ only if the hole width increased. Peak load value decreased by $7.71 \%, 8.04 \%$ and $11.33 \%$ only if the hole height increased. It was found that the peak load value increased by $1.10 \%$ and $1.57 \%$ only if the hole location changed from the mid-height of the column to the bottom. 

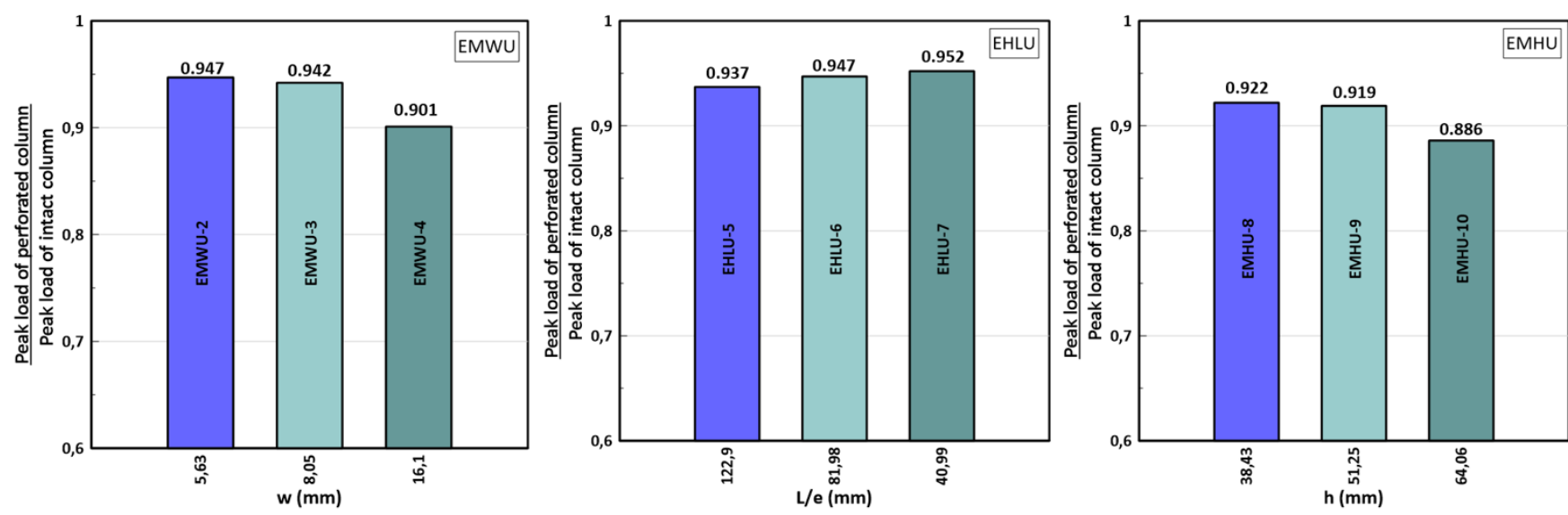

Figure 17 Comparison of peak load of perforated columns with intact column based on numerical analysis

Table 6 Comparison of peak loads obtained by experimental study and Dynaform

\begin{tabular}{|c|c|c|c|c|c|c|c|c|c|}
\hline \multirow{2}{*}{ Sample } & \multicolumn{5}{|c|}{ Peak load (N) } & \multicolumn{4}{|c|}{$\left|F_{E X P}-F_{F E M}\right| / F_{E X P} \times 100 \%$ error } \\
\hline & Dynaform & Test 1 & Test 2 & Test 3 & Test Avg. & Test 1 & Test 2 & Test 3 & Test Avg. \\
\hline INTACT-1 & 71853 & 75099.34 & 74112.66 & 72900.12 & 74037.37 & 4.32 & 3.05 & 1.44 & 2.95 \\
\hline EMWU-2 & 68065.6 & 65162.55 & 68409.76 & 58150.83 & 63907.71 & 4.46 & 0.50 & 17.05 & 6.51 \\
\hline EMWU-3 & 67700.8 & 63976.14 & 64408.34 & 63313.65 & 63899.38 & 5.82 & 5.11 & 6.93 & 5.95 \\
\hline EMWU-4 & 64791.9 & 60879.25 & 58301.79 & 62332.54 & 60504.53 & 6.43 & 11.13 & 3.95 & 7.09 \\
\hline EHLU-5 & 67363.7 & 58827.42 & 61939.94 & 64791.04 & 61852.80 & 14.51 & 8.76 & 3.97 & 8.91 \\
\hline EHLU-6 & 68107.3 & 53458.84 & 64447.44 & 64174.96 & 60693.75 & 27.40 & 5.68 & 6.13 & 12.21 \\
\hline EHLU-7 & 68426.2 & 59376.05 & 66903.84 & 67628.82 & 64636.24 & 15.24 & 2.28 & 1.18 & 5.86 \\
\hline EMHU-8 & 66312.7 & 49652.60 & 58186.38 & 62278.67 & 56705.88 & 33.55 & 13.97 & 6.48 & 16.94 \\
\hline EMHU-9 & 66071.7 & 63752.54 & 65586.26 & 59884.62 & 63074.47 & 3.64 & 0.74 & 10.33 & 4.75 \\
\hline \multirow[t]{2}{*}{ EMHU-10 } & 63706.5 & 59046.23 & 57543.97 & 58971.48 & 58520.56 & 7.89 & 10.71 & 8.03 & 8.86 \\
\hline & & & & & & & & \multicolumn{2}{|c|}{ Avg. error $8 \%$} \\
\hline
\end{tabular}

The average difference between peak loads of the experimental and numerical results calculated $8 \%$ (Table 6). The peak load value difference between the two types of modeling is minimal. The difference between the peak loads of the experimental and numerical models can be attributed to the effect of the top and bottom plates used to cover the cylinders to create fixed boundary condition.

\section{PARAMETRIC STUDY}

The purpose of this study is to obtain optimal dimensions for the desired buckling load. The desired buckling load value is the highest. Therefore, the 'bigger is the best' $\mathrm{S} / \mathrm{N}$ ratio was chosen in the Minitab program. The analysis were carried out according to the Taguchi L9 orthogonal array and the signal/noise (S/N) ratio was taken as a basis in evaluating the buckling loads. In the analysis, hole width, place of hole and hole height were chosen as control factors. Accordingly, the peak load was determined as an response. Determined control factors and levels are given in Table 7 and Table 8 shows the L9 orthogonal array.

Table 7 Control factors and levels used in orthogonal array matrix

\begin{tabular}{ccccc}
\hline \multirow{2}{*}{ Sembol } & Factors & \multicolumn{3}{c}{ Levels } \\
\cline { 3 - 5 } & & $\mathbf{1}$ & $\mathbf{2}$ & $\mathbf{3}$ \\
\hline A & Hole width $(\mathrm{mm})$ & 5.63 & 8.05 & 16.10 \\
B & Place of hole $(\mathrm{e} / \mathrm{L})$ & 0.125 & 0.25 & 0.5 \\
C & Hole height $(\mathrm{mm})$ & 25.625 & 38.43 & 64.06 \\
\hline
\end{tabular}


Table 8 L9 orthogonal array

\begin{tabular}{cccc}
\hline Exp. no & Hole width (A) & Place of hole (B) & Hole height (C) \\
\hline $\mathbf{1}$ & 1 & 1 & 1 \\
$\mathbf{2}$ & 1 & 2 & 2 \\
$\mathbf{3}$ & 1 & 3 & 3 \\
4 & 2 & 1 & 2 \\
5 & 2 & 2 & 3 \\
6 & 2 & 3 & 1 \\
7 & 3 & 1 & 3 \\
8 & 3 & 2 & 1 \\
9 & 3 & 3 & 2 \\
\hline
\end{tabular}

Analysis conditions and buckling loads obtained after analysis are given in Table 9. Taguchi method identifies the optimal conditions in three categories: smaller-the-better, larger-the-better and nominal-the-better Krishnaiah, K., Shahabudeen, P. (2012)

Nominal is the best:

$$
\frac{\mathrm{S}}{\mathrm{N}}=10 \log \left(\frac{\overline{\mathrm{y}}}{\mathrm{s}_{\mathrm{y}}^{2}}\right)
$$

Larger is better:

$$
\begin{aligned}
& \frac{\mathrm{s}}{\mathrm{N}}=-10 \log \left(\frac{1}{\mathrm{n}} \sum_{\mathrm{i}}^{\mathrm{n}} \frac{1}{\mathrm{y}_{\mathrm{i}}{ }^{2}}\right) \\
& \frac{\mathrm{s}}{\mathrm{N}}=-10 \log \left(\frac{1}{\mathrm{n}} \sum_{\mathrm{i}}^{\mathrm{n}} \mathrm{y}_{\mathrm{i}}^{2}\right)
\end{aligned}
$$

Where $y_{i}$ is the mean of all observation values, $s_{y}^{2}$ is the variance for $y, n$ number of experiments and $y_{i}$ is the observation values. In this study, the formula given in equation (6) was used to determine $\mathrm{S} / \mathrm{N}$ values.

The main effects of control factors on $\mathrm{S} / \mathrm{N}$ ratio are given in Table 10 . The level with the highest value in $\mathrm{S} / \mathrm{N}$ ratio for each control factor means the best level for that factor.

Thus, the best factor/level combination has been identified as A1, B1 and C1. Graph of S/N ratio of control factors for buckling load is shown in Figure 18. When the graphic is analyzed, it is seen that A1, B1 and C1 experiment

\begin{tabular}{|c|c|c|c|c|c|}
\hline Exp. no & Hole width (mm) & Place of hole (e/L ratio) & Hole height (mm) & Peak load & (N) \\
\hline 1 & 5.63 & 0.125 & 25.625 & 69938.5 & \\
\hline 2 & 5.63 & 0.25 & 38.430 & 69205.9 & \\
\hline 3 & 5.63 & 0.5 & 64.060 & 68300.4 & \\
\hline 4 & 8.05 & 0.125 & 38.430 & 69189.6 & \\
\hline 5 & 8.05 & 0.25 & 64.060 & 68912.6 & \\
\hline 6 & 8.05 & 0.5 & 25.625 & 68120.5 & \\
\hline 7 & 16.10 & 0.125 & 64.060 & 68071.6 & \\
\hline 8 & 16.10 & 0.25 & 25.625 & 67637.2 & \\
\hline 9 & 16.10 & 0.5 & 38.430 & 64690.4 & \\
\hline
\end{tabular}
combination is the best factor combination according to $\mathrm{S} / \mathrm{N}$ ratio.

Table 9 Analysis conditions, buckling load values

Table 10 Optimum conditions by utilizing $\mathrm{S} / \mathrm{N}$ ratio

\begin{tabular}{cccccc}
\hline Factors & Level 1 & Level 2 & Level 3 & Max-Min & Optimum \\
\hline Hole width & $96.80^{*}$ & 96.74 & 96.49 & 0.31 & A1 \\
Place of hole & $96.78^{*}$ & 96.72 & 96.52 & 0.26 & B1 \\
Hole height & $96.72^{*}$ & 96.61 & 96.70 & 0.11 & C1 \\
\hline
\end{tabular}


The effect levels of the variables on the buckling load were determined by applying variance analysis (ANOVA) with 95\% confidence interval to the experimental results. ANOVA results are seen in Table 11. It is seen from the table that the most important factor on the buckling load is the hole width. In addition, when the contributions of the factors are analyzed; hole width effect $51.97 \%$, place of hole effect $37.11 \%$; the hole height effect is seen to be $7.22 \%$.

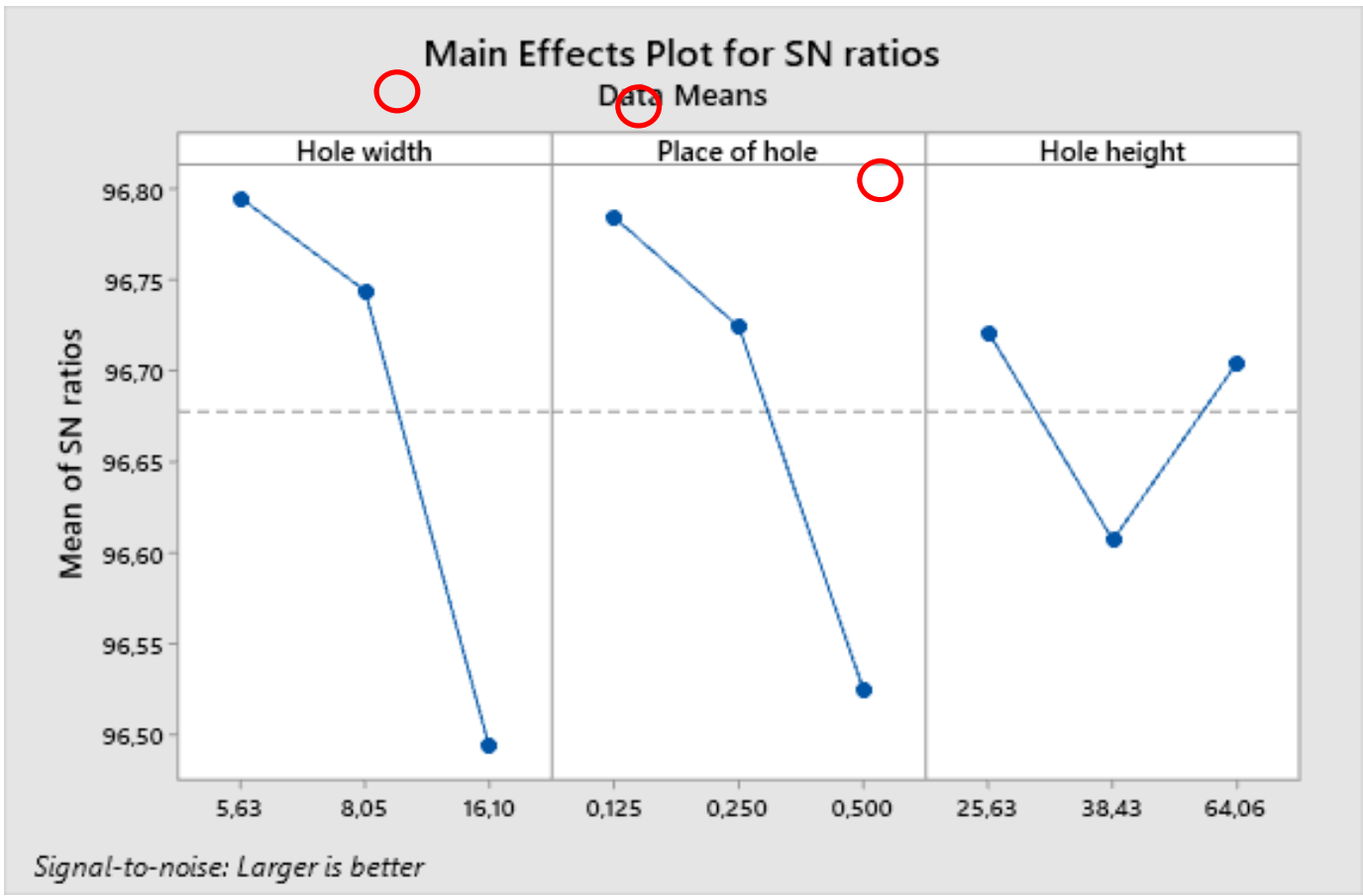

Figure 18. Main effects plot for $\mathrm{S} / \mathrm{N}$ ratios

The effect levels of the variables on the buckling load were determined by applying variance analysis (ANOVA) with 95\% confidence interval to the experimental results. ANOVA results are seen in Table 11. It is seen from the table that the most important factor on the buckling load is the hole width. In addition, when the contributions of the factors are analyzed; hole width effect $51.97 \%$, place of hole effect $37.11 \%$; the hole height effect is seen to be $7.22 \%$.

Table 11 ANOVA results according to the Taguchi L9 experiment design

\begin{tabular}{ccccccc}
\hline Factors & DF & Adj SS & Adj MS & F-Value & P-Value & Contrubution (\%) \\
\hline Hole width & 2 & 9449684 & 4724842 & 14.09 & 0.066 & 51.97 \\
Place of hole & 2 & 6747134 & 3373567 & 10.06 & 0.090 & 37.11 \\
Hole height & 2 & 1313040 & 656520 & 1.96 & 0.338 & 7.22 \\
Error & 2 & 670485 & 335243 & - & - & 3.7 \\
Total & 8 & 18180344 & - & - & - & 100 \\
\hline
\end{tabular}

DF: degrees of fredom, MS: mean square, SS: sum of squares

When a ranking is made by taking into consideration the order of importance of the factors, the factors are listed as $A, B$ and $C$. A and B factors appear to have a greater effect on buckling load.

The coefficient of determation $\left(R^{2}\right)$ obtained as a result of the regression equations is the ratio of the dependent variable's explanatory variable to the unexplained amount in the model. The closer the coefficient of determation $\left(R^{2}\right)$ to 1 in the regression results, the greater part of the change in the dependent variable can be explained by the independent variable. In the regression equation coefficient table; Coef: Indicates the coefficients of the values, Coef SE: Standard error in the coefficients, $T$ : The result of the test statistics, $P$ : Whether the regression analysis is significant. If $P$ $<0.05$, it was concluded that the independent variable was effective on the dependent variable in the regression equation Asilturk and Akkus (2011).

First order regression equation obtained for buckling values is given in equation (8)

Peak Load $=72065-228.5 w-5523(e / L)+1.0 h$ 
The coefficient of determation $\left(\mathrm{R}^{2}\right)$ for the buckling load in the first order regression equation is $88.52 \%$. It can be mentioned that there is a strong relationship between the variables because it is close to $88.52 \%$ of the change in the dependent variable can be explained by independent variables Table 12.

Table 12 1st order regression equation coefficients for buckling load

\begin{tabular}{ccccc}
\hline Term & Coef & SE Coef & T-Value & P-Value \\
\hline Constant & 72065 & 877 & 82.20 & 0.000 \\
Hole width & -228.5 & 48.1 & -4.75 & 0.005 \\
Place of hole & -5523 & 1382 & -4.00 & 0.010 \\
Hole height & 1.0 & 13.5 & 0.08 & 0.942 \\
\hline
\end{tabular}

The experimental, 1st degree regression and Taguchi method estimation values for the peak load are given in Table 13. When Table 12 is examined, the lowest mean error value is $0.37 \%$ Taguchi method estimated values.

Table 13 Experimental, 1st order regression and Taguchi method predicted values for peak load

\begin{tabular}{|c|c|c|c|c|c|c|}
\hline \multirow{2}{*}{ Exp. No } & \multicolumn{3}{|c|}{ Taguchi methods } & \multicolumn{3}{|c|}{ First order regression equation } \\
\hline & Experimental & Estimated & Error (\%) & Experimental & Estimated & Error (\%) \\
\hline 1 & 69938.5 & 70320.9 & 0.55 & 69938.5 & 70113.8 & 0.25 \\
\hline 2 & 69205.9 & 68969.6 & 0.34 & 69205.9 & 69436.2 & 0.33 \\
\hline 3 & 68300.4 & 68154.3 & 0.21 & 68300.4 & 68081.1 & 0.32 \\
\hline 4 & 69189.6 & 69043.5 & 0.21 & 69189.6 & 69573.6 & 0.55 \\
\hline 5 & 68912.6 & 69295.1 & 0.56 & 68912.6 & 68908.8 & 0.01 \\
\hline 6 & 68120.5 & 67884.1 & 0.35 & 68120.5 & 67489.7 & 0.93 \\
\hline 7 & 68071.6 & 67835.2 & 0.35 & 68071.6 & 67759.8 & 0.46 \\
\hline 8 & 67637.2 & 67491.1 & 0.22 & 67637.2 & 67031.1 & 0.90 \\
\hline \multirow[t]{2}{*}{9} & 64690.4 & 65072.9 & 0.59 & 64690.4 & 65663.1 & 1.50 \\
\hline & & Avg. error & $0.37(\%)$ & & Avg. error & $0.58(\%)$ \\
\hline
\end{tabular}

\section{CONCLUSIONS}

The effects of change of hole width, place of hole and hole height parameters on buckling load were calculated by finite element analysis and experimental studies.

1. After the finite element model of the intact sample was created, the peak load value calculated under axial load was compared with the theoretical formula in the literature. $2.54 \%$ error was calculated between the theoretical load value and the peak load obtained by FE analysis.

2. When the load-axial shortening behavior obtained by the experimental and FE results were compared, the results were found to be consistent. After the numerical method was validated, the peak load results were examined depending on the change of parameters. As a result of the review;

- Peak load value decreased by 5,27\%, 5,78\% and 9,83\% only if the hole width increased.

- $\quad$ Peak load value decreased by $7.71 \%, 8.04 \%$ and $11.33 \%$ only if the hole height increased.

- It was found that the peak load value increased by $1.10 \%$ and $1.57 \%$ only if the hole location changed from the midheight of the column to the bottom.

3. It is determined that the deformation shapes obtained by using both methods are similar. When the axial load was applied to the intact sample, a collar-shaped (elephant foot) collapse began at the top of the column. For the perforated columns, outward folding mechanisms were formed in the hole region.

4. The average total energy absorption value of the perforated columns was calculated to be $1752.1 \mathrm{~J}$. When this average value is compared with the intact sample, the total energy absorption capability of the perforated columns was determined that it decreased by $82.82 \%$.

5. It was carried out on optimization of the factors affecting buckling load by using Taguchi method. Signal/noise ratios were determined by calculating the hole width, place of hole and hole height conditions that maximize the buckling 
load. When the optimum values obtained using the Taguchi method are examined; if the hole width is $5.63 \mathrm{~mm}$, place of hole (e/L) is 0.125 and the hole height is $25.63 \mathrm{~mm}$, the buckling load has been found to be maximum.

6. According to ANOVA results, the most effective parameter on buckling load was hole width (51.97\%), place of hole (37.11\%) and hole height (7.22\%), respectively.

7. As a result of estimation experiments, the average error rate was calculated as $0.58 \%$ using the first order mathematical equation. In the estimation of the Taguchi method, the average error rate was calculated as $0.37 \%$. It has been revealed that the Taguchi method can be used safely in calculating the buckling load of the perforated columns.

Author's Contributions: Conceptualization, $\mathrm{T}$ Bolukbas and $\mathrm{OH}$ Mete; Methodology, $\mathrm{T}$ Bolukbas and OH Mete; Investigation, T Bolukbas; Writing - original draft, T Bolukbas; Writing - review \& editing, T Bolukbas and OH Mete; Validation, T Bolukbas; Visualization, T Bolukbas; Resources, T Bolukbas; Supervision, $\mathrm{OH}$ Mete.

Editor: Marcílio Alves.

\section{References}

Asilturk, I., Akkus, H. (2011). "Determining the effect of cutting parameters on surface roughness in hard turning using the Taguchi method", Measurement, vol. 44, pp.1697-1704.

Bari, M. (2015). "A finite element study of shell and solid element performance in crash-box simulations", Thesis, University West, Sweden, p.6.

Cottrel, A. H. (1964). “The Mechanical Properties of Matter” John Wiley and Sons, Inc., New York, p.289.

Feng, R., Mou, X., Chen, A., Ma, Y. (2016). "Tests of aluminium alloy CHS columns with circular openings", Thin-Walled Structures 109:113-131, DOI:10.1016/j.tws.2016.09.019

Ghazijahani, T.G., Jiao, H., Holloway, D. (2015). "Structural behavior of shells with different cutouts under compression: An experimental study", Journal of Constructional Steel Research 105:129-137, DOI:10.1016/j.jcsr.2014.10.020

Hou, B., Lu X., Zhu, X. (2019). “Axial compression performance and failure modes of 304 stainless-steel/GFRP hybrid tubes” Materials Resarch Express, Volume 6, Number 5, DOI:10.1088/2053-1591/ab0154

Ifayefunmi O., Blachut, J., (2011) "The effect of shape, thickness and boundary imperfections on plastic buckling of cones", 30th International Conference on Ocean, Offshore and Arctic Engineering, OMAE2011-49055, ASME,vol.2,NY,USA, DOI: 10.1115/OMAE2011-49055

Ifayefunmi, O. (2016). "Buckling behavior of axially compressed cylindrical shells: Comparison of theoretical and experimental data", Thin-Walled Structures 98:558-564, DOI:10.1016/j.tws.2015.10.027

Jullien, J.F., Limam, A. (1998). "Effects of openings of the buckling of cylindrical shells subjected to axial compression”, ThinWalled Structures 31 187-202, DOI:10.1016/S0263-8231(98)00003-2

Karagah, H., Shi, C., Dawood, M., Belarbi, A. (2015). “Experimental investigation of short steel columns with localized corrosion", Thin-Walled Structures 87:191-199, DOI:10.1016/j.tws.2014.11.009

Krishnaiah, K., Shahabudeen, P. (2012) “Applied design of experiments and Taguchi methods” PHI Learning Pvt. Ltd., Delhi, India

Lee, S. E., Sahin, S., Rigo, P., Park, M., Paik, J. K. (2017). "Ultimate strength of cylindrical shells with cutouts", Ultimate strength of cylindrical shells with cutouts, Ships and Offshore Structures, 12:sup1, S153-S173, DOI:10.1080/17445302.2016.1271592

Ls-Dyna, (2007) “Keyword user's manual” Volume I, Version 971, Livermore Software Technology Corporation (LSTC), Livermore, California, p.1478.

Nazari, M., Khedmati, M.R., Khalaj, A. F. (2014). "A numerical investigation into ultimate strength and buckling behavior of locally corroded steel tubular members", Latin American Journal of Solids and Structures, [online], vol.11, n.6, pp.1063-1076. ISSN 1679-7825., DOI:10.1590/S1679-78252014000600010 
Nabati, A., Ghazijahani, T., G. (2020) "CFRP-reinforced circular steel tubes with cutout under axial loading”, Journal of Constructional Steel Research 164;105775, DOI:10.1016/j.jcsr.2019.105775

Oszvald, K. (2014). "Buckling of corroded steel angle members under compression", PhD Dissertion

Rouzegar, J., Assaee, H., Elahi, S. M., Asiaei, H. (2018). "Axial crushing of perforated metal and composite-metal tubes", Journal of the Brazilian Society of Mechanical Sciences and Engineering, DOI:10.1007/s40430-018-1266-6

Rouzegar, J., Elahi, M. (2016). "Experimental and numerical study on axial compression of metal tubes with holes”, International Journal of Mechanical and Production Engineering, ISSN:2320-2092.

Shariati, M., Rokhi, M. M. (2008). “Numerical and experimental investigations on buckling of steel cylindrical shells with elliptical cutout subject to axial compression”, Thin-Walled Structures 46 1251-1261, DOI:10.1016/j.tws.2008.02.005

Shariati, M., Sedighi, M., Saemi, J., Allahbakhsh, H. R. (2010). "A numerical and experimental study on buckling of cylindrical panels subjected to compressive axial load" Strojniški vestnik - Journal of Mechanical Engineering 56:10, 609-618

Stelzmann, U. (2010). “Die grosse Elementbibliothek in LS-DYNA-Wann nimmt man was?", ANSYS Conference \& $28^{\text {th }}$ CADFEM Users.

Timoshenko, S. P., Gere, J. M. (1961). Theory of Elastic Stability, 2nd edition. NewYork: McGraw-Hill

Toda, S. (1983). "Buckling of cylinders with cutouts under axial compression", Experimental Mechanics, 23: 414-417, DOI: 10.1007/BF02330057

Umbarkar, K.R., Patton, L. M., Singh, K. D. (2013). “Effect of single circular perforation in lean duplex stainless steel (LDSS) hollow circular stub columns under pure axial compression", Thin-Walled Structures 68:18-25, DOI:10.1016/j.tws.2013.02.015

Vaz, M. A., Cyrino, J. C. R., Hernandez, I. D., Zegarra V. D., Martinez J. L., Liang D. A. (2018). "Experimental and numerical analyses of the ultimate compressive strength of perforated offshore tubular members", Marine Structures ISSN:0951-8339, DOI:10.1016/j.marstruc.2017.10.010

Zhao, C., Niu, J., Zhang, Q., Zhao, C., Xie, J. (2018). "Buckling behavior of a thin-walled cylinder shell with the cutout imperfections", Mechanics of Advanced Materials and Structures ISSN:1537-6494, DOI:10.1080/15376494.2018.1444225 